\title{
Developmental Switch in the Contribution of Presynaptic and Postsynaptic NMDA Receptors to Long-Term Depression
}

\author{
Rebekah Corlew, ${ }^{1}$ Yun Wang, ${ }^{4}$ Haben Ghermazien, ${ }^{5}$ Alev Erisir, ${ }^{5}$ and Benjamin D. Philpot ${ }^{1,2,3}$ \\ ${ }^{1}$ Curriculum in Neurobiology, ${ }^{2}$ Neuroscience Center, and ${ }^{3}$ Department of Cell and Molecular Physiology, University of North Carolina, Chapel Hill, North \\ Carolina 27599, ${ }^{4}$ Department of Neurology, Caritas St. Elizabeth's Medical Center, Tufts University School of Medicine, Boston, Massachusetts 02135, and \\ ${ }^{5}$ Department of Psychology, University of Virginia, Charlottesville, Virginia 22904
}

\begin{abstract}
NMDA receptor (NMDAR) activation is required for many forms of learning and memory as well as sensory system receptive field plasticity, yet the relative contribution of presynaptic and postsynaptic NMDARs over cortical development remains unknown. Here we demonstrate a rapid developmental loss of functional presynaptic NMDARs in the neocortex. Presynaptic NMDARs enhance neurotransmitter release at synapses onto visual cortex pyramidal cells in young mice [before postnatal day 20 (P20)], but they have no apparent effect after the onset of the critical period for receptive field plasticity ( $>$ P23). Immunoelectron microscopy revealed that the loss of presynaptic NMDAR function is likely attributable in part to a $50 \%$ reduction in the prevalence of presynaptic NMDARs. Coincident with the observed loss of presynaptic NMDAR function, there is an abrupt change in the mechanisms of timing-dependent long-term depression (tLTD). Induction of tLTD before the onset of the critical period requires activation of presynaptic but not postsynaptic NMDARs, whereas the induction of tLTD in older mice requires activation of postsynaptic NMDARs. By demonstrating that both presynaptic and postsynaptic NMDARs contribute to the induction of synaptic plasticity and that their relative roles shift over development, our findings define a novel, and perhaps general, property of synaptic plasticity in emerging cortical circuits.
\end{abstract}

Key words: presynaptic; NMDA receptor; long-term depression; visual cortex; spike timing-dependent plasticity; electron microscopy

\section{Introduction}

Synaptic connections in sensory cortices such as the primary visual cortex are initially sculpted in an experience-independent manner, allowing rough cortical maps and receptive field properties to emerge in the absence of sensory experience (Rakic, 1977; Mower et al., 1985; Stryker and Harris, 1986; Horton and Hocking, 1996; Crowley and Katz, 1999; Feller and Scanziani, 2005). Visual experience begins sculpting receptive field properties at eye opening (Smith and Trachtenberg, 2007). This is followed by a "critical period" during which ocular dominance plasticity is particularly robust and receptive field properties are additionally refined in an experience-dependent manner (Fox and Zahs, 1994; Berardi et al., 2000; Sengpiel and Kind, 2002; Hensch, 2004). Activation of the NMDA-type glutamate receptors (NMDARs) is required for many experience-dependent forms of plasticity as well as some forms of activity-dependent plasticity that do not rely on sensory experience (Bear and Rit-

Received Dec. 19, 2006; revised July 17, 2007; accepted July 19, 2007.

This work was supported by the National Science Foundation, a Ruth L. Kirchenstein National Research Service Award (R.C.), the Zucker Research Center for Women Scholars and Charlton Award (Y.W.), a University of North Carolina Career Development Award, NARSAD, and the Whitehall Foundation (B.D.P.). We thank J. de Marchena, M. Ehlers, R. Froemke, M. Henson, P. Manis, A. Roberts, O. Palmer, and P. J. Sjöström for constructive advice on experiments and this manuscript.

Correspondence should be addressed to Benjamin D. Philpot, University of North Carolina, Campus Box 7545, 105 Mason Farm Road, Chapel Hill, NC 27599-7545. E-mail: bphilpot@med.unc.edu.

DOI:10.1523/JNEUROSCI.5494-06.2007

Copyright $\odot 2007$ Society for Neuroscience $\quad$ 0270-6474/07/279835-11\$15.00/0 tenhouse, 1999; Iwasato et al., 2000; Malenka and Bear, 2004). Thus, an important goal is to establish the precise role of NMDARs in key forms of cortical plasticity and whether this changes over development.

NMDARs were traditionally thought to exert their influences postsynaptically, and their presynaptic existence has been largely ignored. A surprising finding is that NMDARs are anatomically expressed presynaptically (Aoki et al., 1994; Charton et al., 1999), and these presynaptic receptors are involved in both neurotransmission and plasticity (Berretta and Jones, 1996; Woodhall et al., 2001; Casado et al., 2002; Humeau et al., 2003; Bardoni et al., 2004; Duguid and Smart, 2004; Mameli et al., 2005; Duguid and Sjöström, 2006; Lien et al., 2006; Yang et al., 2006). For example, timing-dependent long-term depression (tLTD) between layer 5 (L5) pyramidal cells in the visual cortex requires the simultaneous activation of presynaptic NMDARs and cannabinoid receptors (Sjöström et al., 2003). This tLTD is expressed presynaptically as a reduction in the probability of neurotransmitter release. Presynaptic NMDARs are also involved in neurotransmission in L2/3 of visual cortex (Li and Han, 2007) and tLTD induction at L2/3 in barrel cortex of young rodents (Bender et al., 2006b). Although growing evidence suggests an important role for presynaptic NMDARs early in development (Lien et al., 2006), it remains unknown whether presynaptic NMDARs are regulated in a laminar or developmental manner.

Here we examined the laminar and developmental profile of 
presynaptic NMDAR function in the visual cortex, a well studied model for sensory map plasticity (Fox and Zahs, 1994; Katz and Shatz, 1996; Bear and Rittenhouse, 1999; Berardi et al., 2000; Sengpiel and Kind, 2002; Hensch, 2004; Taha and Stryker, 2005; Hofer et al., 2006). We demonstrate that although presynaptic NMDARs enhance spontaneous neurotransmission onto pyramidal neurons in L2/3, L4, and L5 early in development, there is an abrupt loss of this function at the onset of the critical period. Furthermore, presynaptic, but not postsynaptic, NMDARs are required for the induction of tLTD at the L4 $\rightarrow$ L2/3 synapse during the precritical period. At the onset of the critical period, however, a dramatic loss of presynaptic NMDARs appears to trigger the emergence of a postsynaptic requirement of NMDARs for tLTD.

\section{Materials and Methods}

Subjects. C57BL/6 mice were purchased from Charles River Laboratories (Wilmington, MA) and used between postnatal day 7 (P7) and P90. Mice were maintained on a $12 \mathrm{~h}$ light/dark cycle and fed ad libitum. All experiments were performed under the animal care guidelines for Tufts University School of Medicine, the University of Virginia, and the University of North Carolina at Chapel Hill.

Cortical slice preparation. Mice were anesthetized with pentobarbital sodium $(40 \mathrm{mg} / \mathrm{kg}$, i.p.) and decapitated after disappearance of corneal reflexes. Brains were rapidly removed and immersed in ice-cold dissection buffer [composition (in $\mathrm{mm}$ ), $87 \mathrm{NaCl}, 2.5 \mathrm{KCl}, 1.25$ $\mathrm{NaH}_{2} \mathrm{PO}_{4}, 25 \mathrm{NaHCO}_{3}, 75$ sucrose, $10 \mathrm{dex}-$ trose, 1.3 ascorbic acid, $7 \mathrm{MgCl}_{2}$, and $0.5 \mathrm{CaCl}_{2}$ ] bubbled with $95 \% \mathrm{O}_{2}$ and $5 \% \mathrm{CO}_{2}$. The visual cortex was rapidly dissected, and $350 \mu \mathrm{m}$ coronal slices were prepared using a vibrating microtome (VT1000S; Leica, Bannockburn, IL). Slices were allowed to recover for $20 \mathrm{~min}$ in a submersion chamber at $35^{\circ} \mathrm{C}$ filled with warmed artificial CSF (ACSF) [(in mM) 124 $\mathrm{NaCl}, 3 \mathrm{KCl}, 1.25 \mathrm{Na}_{2} \mathrm{PO}_{4}, 26 \mathrm{NaHCO}_{3}, 1$ $\mathrm{MgCl}_{2}, 2 \mathrm{CaCl}_{2}$, and $20 \mathrm{D}$-glucose, saturated with $95 \% \mathrm{O}_{2}$ and $5 \% \mathrm{CO}_{2} ; \sim 315 \mathrm{mOsm}$ and $\mathrm{pH} \sim 7.25$ ] and then kept at room temperature until use. For recordings, visual cortex slices were placed in a submersion chamber, maintained at $30^{\circ} \mathrm{C}$, and perfused with oxygenated ACSF.

Voltage-clamp recordings. Patch pipettes were pulled from thick-walled borosilicate glass. Open tip resistances were 3-6 $\mathrm{M} \Omega$ when pipettes were filled with an internal solution typically containing (in $\mathrm{mM}$ ) $20 \mathrm{KCl}, 100(\mathrm{~K})$ gluconate, 10 HEPES, $4(\mathrm{Mg})$ ATP, $0.3(\mathrm{Na}) \mathrm{GTP}$, and $10(\mathrm{Na})$ phosphocreatine with $\mathrm{pH}$ adjusted to 7.25 and osmolarity adjusted to $\sim 300 \mathrm{mOsm}$ with sucrose or double-distilled $\mathrm{H}_{2} \mathrm{O}$. For isolating NMDARmediated currents, internal solution contained the following (in $\mathrm{mm}$ ): 102 cesium gluconate, 5 tetraethylammonium-chloride, $3.7 \mathrm{NaCl}, 20$
A

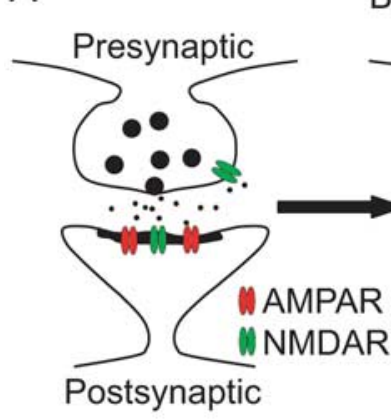

Block postsynaptic NMDARs

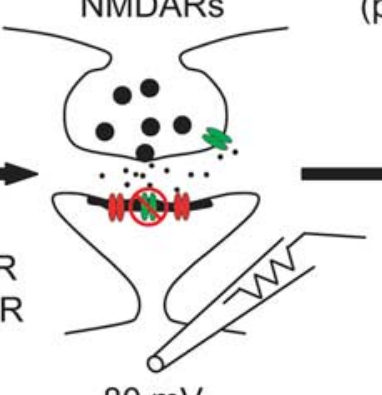

$-80 \mathrm{mV}$

$-80 \mathrm{mV}$
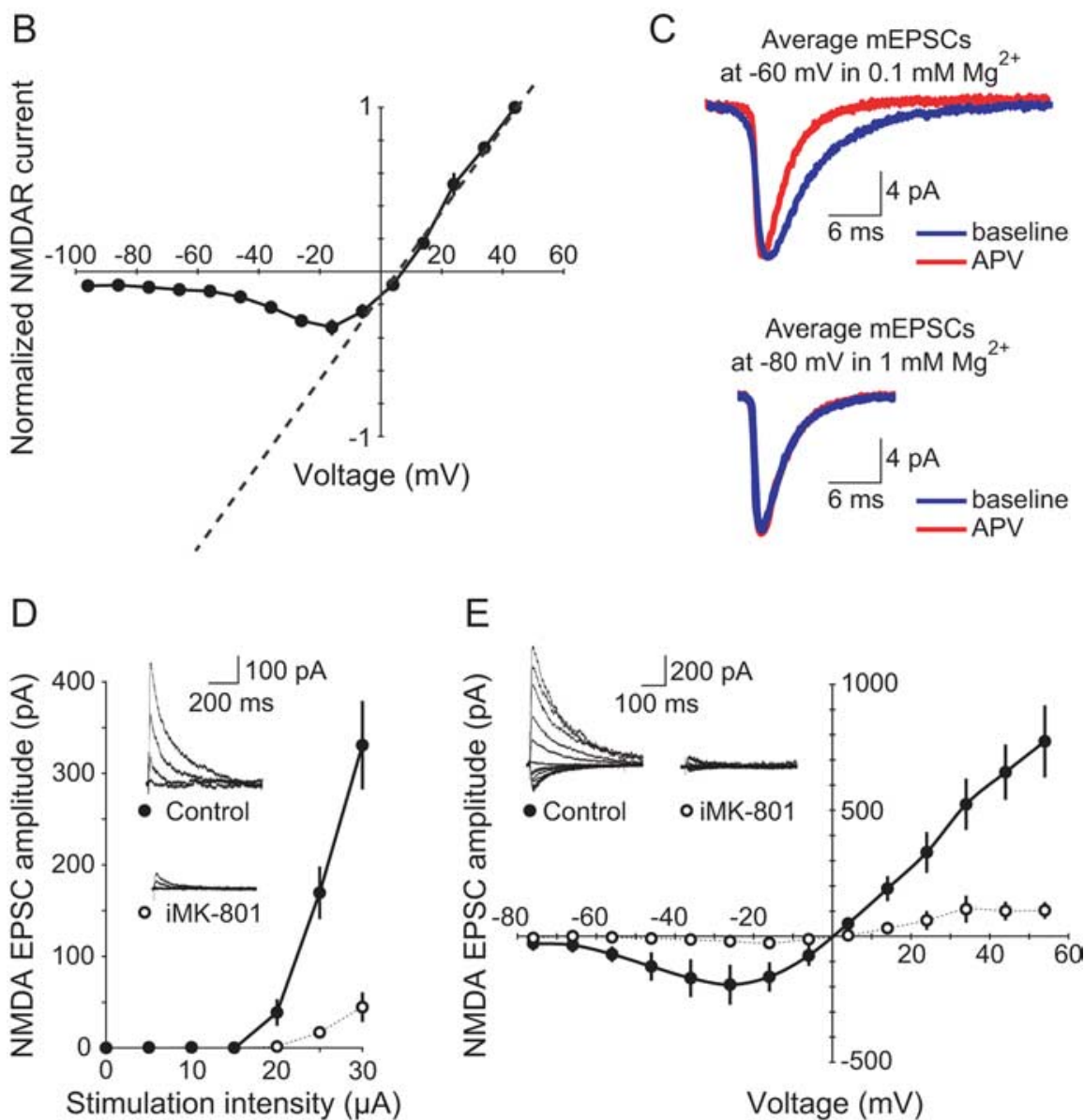

Figure 1. Postsynaptic NMDAR function can be blocked with either hyperpolarization or the inclusion of MK-801 in the postsynaptic recording pipette (iMK-801). A, Model depicting the commonly used experimental protocol for detecting functional presynaptic NMDARs. After blocking postsynaptic NMDARs with strong hyperpolarization (or iMK-801), the role of presynaptic NMDARs in synaptic transmission can be tested by blocking the remaining presynaptic NMDARs with bath application of APV. $\boldsymbol{B}$, Normalized $I-V$ relationship at the $L 4 \rightarrow L 2 / 3$ synapse of pharmacologically isolated NMDAR-mediated EPSCs. Dotted line is a fit to the linear portion of the $I-V$ relationship. Note the strong block of NMDAR currents by hyperpolarization $(n=11$; average age of animals, $\sim$ P24). C, Top, APV blocks the NMDAR component of mEPSCs recorded at $-60 \mathrm{mV}$ in $0.1 \mathrm{~mm} \mathrm{Mg}^{2+}$. Bottom, APV has no postsynaptic effect on the amplitude or kinetics of $\mathrm{mEPSCs}$ recorded at $-80 \mathrm{mV}$ in $1 \mathrm{~mm} \mathrm{Mg}{ }^{2+}$, suggesting that the mEPSC currents are mediated by AMPA receptors and that the NMDAR component is nonexistent or negligible. $D$, Synaptic I- 0 relationship for L2/3 cells recorded at $+24 \mathrm{mV}$ with iMK- 801 (open circles) or without iMK-801 (filled circles). Inset, Representative traces for control and iMK-801 I-0 curves. Even at this depolarized holding voltage, iMK-801 blocks $>96 \%$ of the NMDAR current evoked at $20 \mu \mathrm{A}$, which is our average stimulation intensity. $\boldsymbol{E}$, Synaptic $/-V$ relationship for the same cells shown in $\boldsymbol{D}$ showing that, with iMK-801 and a stimulation of $30 \mu \mathrm{A}$, the NMDAR current is completely blocked $(n=4)$ compared with control $(n=5)$ at $-65 \mathrm{mV}$. Inset, Representative traces for the $I-V$ recordings. 
A

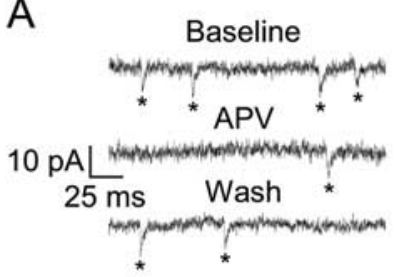

$\mathrm{C}_{1}$

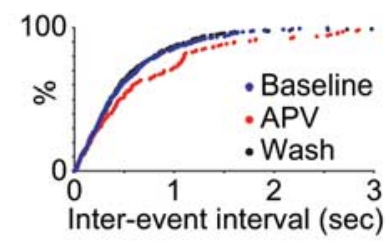

$D_{1}$

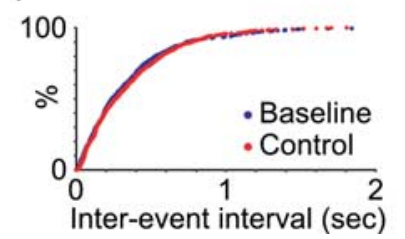

B

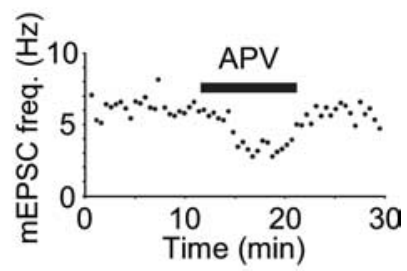

$\mathrm{C}_{2}$

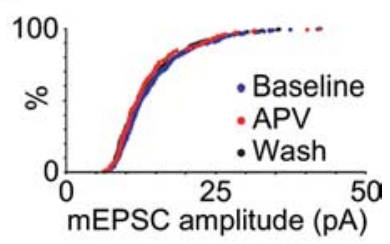

$\mathrm{D}_{2}$

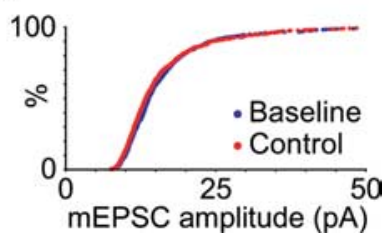

Figure 2. Presynaptic NMDARs tonically increase the probability of neurotransmitter release onto $\mathrm{L} 2 / 3$ pyramidal cells in the mouse visual cortex. $A$, Example recording from an $\mathrm{L} 2 / 3$ pyramidal cell from a P16 mouse demonstrating that $100 \mu \mathrm{m}$ APV reversibly reduces mEPSC frequency. Events are indicated by asterisks. $\boldsymbol{B}$, Example experiment demonstrating that the reduction in mEPSC frequency (freq.) by APV is reversible. $C$, Cumulative probability histograms from an L2/3 pyramidal cell at P16 demonstrating that APV application reversibly increases $\mathrm{mEPSC}$ interevent interval $\left(\boldsymbol{C}_{\mathbf{1}}\right)$ without affecting amplitude $\left(\boldsymbol{C}_{\mathbf{2}}\right)$. $\boldsymbol{D}$, Representative data from a single cell demonstrating that neither interevent interval $\left(\boldsymbol{D}_{1}\right)$ nor amplitude $\left(\boldsymbol{D}_{2}\right)$ changed in the absence of APV treatment. The control cell was recorded for the same duration as experiments in which APV was applied.

HEPES, 0.3 sodium guanosine triphosphate, 4 magnesium adenosine triphosphate, 0.2 EGTA, 10 BAPTA, and 5 QX-314 [N-(2,6dimethylphenylcarbamoylmethyl)triethylammonium] chloride (Alomone Labs, Jerusalem, Israel). Cells were voltage clamped in the whole-cell configuration using a patch-clamp amplifier (Multiclamp 700A; Molecular Devices, Sunnyvale, CA), and data were acquired and analyzed using pCLAMP 9.2 software (Molecular Devices). For current-voltage ( $I-V)$ curves of isolated NMDAR responses, voltage was adjusted for the large $(16 \mathrm{mV})$, empirically determined junction potential of the cesium-based internal solution. Changes in series resistance were monitored throughout the experiment by giving a test pulse and measuring the amplitude of the capacitive current. Only cells with series resistance $<30 \mathrm{M} \Omega$ were included for analysis. No series resistance compensation was applied. Input resistance was monitored throughout the experiment by measuring the amplitude of the steady-state current, filtered at $2 \mathrm{kHz}$, evoked from a test pulse. Only cells with $<30 \%$ change in $R_{\text {input }}, R_{\text {series }}$, and $I_{\text {holding }}$ were included for analysis. EPSCs were evoked from a stimulating electrode (two-conductor cluster electrodes with $75 \mu \mathrm{m}$ tip separation; FHC, Bowdoin, ME). NMDAR currents were pharmacologically isolated by modifying the standard ACSF to contain $4 \mathrm{~mm}$ $\mathrm{Mg}^{2+}, 4 \mathrm{mM} \mathrm{Ca}^{2+}, 1 \mu \mathrm{M}$ glycine, $50 \mu \mathrm{M}$ picrotoxin, and $40 \mu \mathrm{M}$ DNQX or 20 $\mu \mathrm{M}$ CNQX.

Miniature EPSC recordings. Excitatory miniature EPSCs (mEPSCs) were recorded in the presence of blockers for voltage-gated sodium channels [tetrodotoxin (TTX); $200 \mathrm{~nm}$ ] and $\mathrm{GABA}_{\mathrm{A}}$ receptors (picrotoxin; 50 $\mu \mathrm{M})$ as well as $1 \mu \mathrm{M}$ glycine. We recorded AMPA receptor-mediated mEPSCs at negative holding potentials $(-80 \mathrm{mV})$ to block the postsynaptic NMDAR currents and measured mEPSC amplitude and frequency before, during, and after bath application of the NMDAR antagonist D-APV $(50 \mu \mathrm{M})$ or D,L-APV $(100 \mu \mathrm{M})$. D, L-APV is abbreviated as APV

unless otherwise noted. Comparisons were made for (1) the last 4 min of a $10 \mathrm{~min}$ baseline period, (2) the last $4 \mathrm{~min}$ of an 8-10 min window after application of $100 \mu \mathrm{M}$ APV, and (3) the last 4 min after drug washout lasting 15-20 $\mathrm{min}$. We also performed experiments of the same duration without drug application as a demonstration of the stability of the recordings. Events were identified by their rapid rise time $(<3 \mathrm{~ms})$ and were detected using an automatic template detection program (pCLAMP; Molecular Devices) (Clements and Bekkers, 1997). The detection threshold remained constant for the duration of each experiment. All events were manually verified, and only events with a monotonic rise time and exponential decay were included in the analysis. Normalized frequency and amplitudes were used for mEPSC data analysis. Over 150 events, with an average of $\sim 700$ events, were analyzed for each data point for each cell.

tLTD induction and short-term plasticity. The internal recording solutions used for these experiments consisted of the following (in $\mathrm{mM}$ ): 100 (K)gluconate, $20 \mathrm{KCl}, 4$ (Mg)ATP, 10 phosphocreatine, $0.3 \mathrm{GTP}$, and 10 HEPES, with $\mathrm{pH}$ adjusted to 7.25 and osmolarity adjusted to 290-295 mOsm. Some solutions also contained $0.4 \%$ biocytin and/or $(+)-5-$ methyl-10,11-dihydro-5H-dibenzo[a,d]cyclohepten-5,10-imine maleate (MK-801) (0.5-1 mM). Picrotoxin (50 $\mu \mathrm{M})$ was included in the bath solution for a subset of recordings. We chose to bath apply picrotoxin rather than applying it focally. Although the bath application of picrotoxin during recording led to a high attrition rate for experiments as a result of polysynaptic activity, particularly in older mice, the bath application of picrotoxin assured a response free of inhibition. Experiments recorded in the presence or absence of picrotoxin in the younger age group were combined, as they yielded similar results, consistent with previous observations that the properties of spike timing-dependent plasticity are similar with and without the blockade of inhibition (Feldman, 2000; Froemke and Dan, 2002). In the P23-P30 age group, however, tLTD could only be induced in the presence of picrotoxin to block inhibition. Therefore, at this age group experiments with and without picrotoxin were analyzed separately. L2/3 pyramidal cells were recorded in current clamp, and weak stimulation was delivered to L4, which makes a particularly strong and vertically organized projection to L2/3 (Burkhalter, 1989). Extracellular stimulation produced a monophasic and fixed latency response, which we interpreted as predominantly coming from L4 or other vertical inputs. We feel that it is unlikely that we are activating local axon collaterals, because we never evoked antidromic action potentials (APs) at the low stimulation intensities used in these studies. Baseline stimulation was delivered once every 15-18 s. After a 10-15 min stable baseline, AP and EPSP pairings were delivered 75-100 times (at $\sim 0.2 \mathrm{~Hz}$ ) with a postsynaptic action potential produced by brief $(<5 \mathrm{~ms})$ depolarization followed 5-25 ms later by an EPSP evoked by L4 stimulation. After pairing, stimulation was delivered for $30 \mathrm{~min}$ at baseline frequencies. Short-term plasticity (i.e., the rate of synaptic depression) was compared before and after pairing by stimulating six pulses at $30 \mathrm{~Hz}$. Because slices in the older mice were susceptible to polysynaptic activity evoked by $30 \mathrm{~Hz}$ stimulation in picrotoxin, we only induced 30 $\mathrm{Hz}$ stimulation for brief periods (rather than every $18 \mathrm{~s}$ ) before and after the tLTD induction in these older mice.

Synaptic depression analysis. A change in the amount of synaptic depression between the baseline responses and the responses after the induction of tLTD was quantified using a short-term depression (STD) index described by Sjöström et al. (2003). The change in the amount of synaptic depression observed in a train of six EPSPs evoked at $30 \mathrm{~Hz}$ was compared between the average responses in the first $10 \mathrm{~min}$ (baseline) and the last $10 \mathrm{~min}$ (postinduction). Net amplitudes for each EPSP were used. The STD index is calculated as follows:

$$
S T D \text { index }=\frac{\frac{E P S P_{1(\text { postinduction })}}{E P S P_{1(\text { baseline })}}-\frac{1}{5} \sum_{i=2}^{i=6} \frac{E P S P_{i(\text { postinduction })}}{E P S P_{i(\text { baseline })}}}{\frac{E P S P_{1(\text { postinduction })}}{E P S P_{1(\text { baseline })}}} .
$$

Electron microscopy. Mice were given an overdose of Nembutal and perfused transcardially with heparinized Tyrode solution for $3 \mathrm{~min}$, fol- 
lowed by a mixture of $4 \%$ paraformaldehyde (dissolved in $0.1 \mathrm{M}$ phosphate buffer at $\mathrm{pH} 7.4$ ) and $0.5 \%$ gluteraldehyde [electron microscopy (EM) grade; Electron Microscopy Sciences, Hatfield, PA] for $15 \mathrm{~min}$. After perfusions, brains were kept within the skull and postfixed overnight in the same fixative. A vibrating microtome was used to cut $60 \mu \mathrm{m}$ sections coronally through the visual cortex. Sections were treated with $1 \% \mathrm{NaBH}_{4}$ to terminate the crosslinking actions of the fixatives and stored freefloating at $4^{\circ} \mathrm{C}$ in $0.01 \mathrm{M}$ PBS containing $0.05 \%$ sodium azide. To prepare for preembedding immunocytochemistry, sections were rinsed and treated in $1 \%$ bovine serum albumin (BSA) in PBS for $30 \mathrm{~min}$, and they were incubated in a $1 \mu \mathrm{g} / \mathrm{ml}$ dilution of polyclonal rabbit anti-NR1 (Millipore, Billerica, MA) in PBS with 1\% BSA and $0.05 \%$ sodium azide, for $3 \mathrm{~d}$ at room temperature. The sections were then rinsed and incubated in a biotinylated goat anti-rabbit secondary antibody (Vector Laboratories, Burlingame, CA) for $2 \mathrm{~h}$, followed by $2 \mathrm{~h}$ incubation in HRP-conjugated avidin-biotin complex (Vector Laboratories). Immunoreactivity was visualized using diaminobenzidine (DAB; $0.05 \%)$ and $\mathrm{H}_{2} \mathrm{O}_{2}(0.001 \%)$. Deletion of primary antibodies eliminated all specific staining discernible at the EM level.

Immunostained sections were fixed with $2 \%$ glutaraldehyde in phosphate buffer for $10 \mathrm{~min}$, followed by $1 \%$ osmium tetroxide for $1 \mathrm{~h}$. Sections were then dehydrated in a series of alcohols (50\% ethanol, $70 \%$ containing $4 \%$ uranyl acetate, $90 \%$, and $100 \%$ twice), infiltrated with liquid resin (Embed 812; Electron Microscopy Sciences), and placed between two sheets of clear acetate (Aclar; Ted Pella, Redding, CA). The resin was allowed to polymerize $1-2 \mathrm{~d}$ at $60^{\circ} \mathrm{C}$. Sections were drawn with the aid of camera lucida, and the areas to be analyzed by EM were cut and placed on flat surfaces of Beem capsule caps. These capsules then were filled with resin and left in a $60^{\circ} \mathrm{C}$ oven, until the resin in the capsule polymerized. Trapezoids that contained a strip of cortex from the pial surface to the white matter were prepared; these were reexamined on the light microscope to note landmarks for laminar borders. This ensured reliable laminar analysis, as described below. Ultrathin sections were cut using an ultramicrotome (Leica UMC), and these were oriented nearly parallel to the surface of vibratome sections. This approach allows ultrathin sections to be taken from the area in which the antibody penetration is maximal. Sections were examined on a JEOL (Peabody, MA) JEM1010 microscope.

To determine cortical layer borders on the resin-embedded sections, capsule-embedded sections were drawn using camera lucida, and certain landmarks, such as the border of cell-sparse layer 1 and the position of tissue within the resin block, were marked. The drawings from each block were then compared with ultrathin sections obtained from those blocks, and the position of $\mathrm{L} 2 / 3$ was determined within the resin trapezoid. For quantitative EM analysis, the synapse was used as the main counting unit. From each immunostained brain, at least 50 adjacent but nonoverlapping images were captured at $10,000 \times$ magnification, using a 16 megapixel CCD camera (Scientific Instruments and Applications, Duluth, GA). The images were examined at 35,000-60,000× final magnification using ImagePro Express software (Media Cybernetics, Silver Spring, MD). Systematic sweeps were used to locate synapses on each image. Then, the experimenter judged whether the presynaptic or postsynaptic elements of the synapse contained any label and evaluated the type of synaptic contact (symmetric or asymmetric). A second experimenter who was blinded to the experimental conditions reevaluated the images to confirm the quantitative analysis.

Identification of synapses and the DAB label was performed with the following considerations. A synaptic terminal was identified by the pres- ence of at least one synaptic vesicle in contact with a plasma membrane, at least three or more vesicles within the same profile, and the parallel alignment of the postsynaptic plasma membrane with that of the terminal. A postsynaptic density was deemed $\mathrm{DAB}$ positive if it contained an accumulation of black DAB chromogen at the postsynaptic membrane. The chromogen accumulation was invariably darker and irregularly shaped in contrast to the regularly shaped morphology of the unlabeled, gray postsynaptic densities. Profiles that contained DAB accumulation that was not in contact with the postsynaptic membrane were deemed unlabeled. The criterion to classify a presynaptic terminal as DAB positive was the presence of any discernible black DAB accumulation anywhere in the terminal. Typically, DAB accumulation either uniformly filled the terminal or appeared as patches of label attached to the presynaptic membrane or nonsynaptic membranes. Excluding primary antibody from tissue processing following our regular visualization protocol eliminated all specific DAB labeling from our material. From the counts of synapses that are unlabeled or displayed labeling in the presynaptic terminal or at the postsynaptic density, we calculated (1) the prevalence of presynaptic labeling $\left(N_{\text {presynaptic label }} \times 100 / N_{\text {all synapses }}\right)$, (2) the prevalence of postsynaptic labeling $\left(N_{\text {postsynaptic label }} \times 100 / N_{\text {all synapses }}\right)$, and (3) the ratio of presynaptic/postsynaptic label. The number of synapses that were encountered in each brain ranged from 159 to 420 . The difference in the number of synapses examined from each brain was an outcome of the presence of different numbers of synapses within a predetermined number of images captured from each brain. Every synapse from all images was included in the analysis. Two brains each at P16 and P27 were analyzed. The experimenters analyzing the data were blind to either the expected outcome or the ages of the animals.

Pharmacological agents. Unless otherwise noted, all drugs were purchased from Sigma-Aldrich (St. Louis, MO).

Statistics. Values are reported as mean \pm SEM, unless specified otherwise. The nonparametric Kruskal-Wallis test was used to determine statistical significance of cumulative probability histograms. Student's $t$ tests were used at the $p<0.05$ significance level, except where significance was corrected to $p<0.0045$ for multiple comparisons using the Bonferroni method (see Fig. 3). 
Table 1. Data from mEPSC recordings (means \pm SEM)

\begin{tabular}{|c|c|c|c|c|c|c|c|c|c|c|c|c|}
\hline & $\sim P 9$ (P7-P11) & & & $\sim P 16(\mathrm{P} 13-\mathrm{P} 20$ & & & $\sim P 26(P 23-P$ & & & $\sim P 80$ (P72-P9 & 90) & \\
\hline & $L 2 / 3$ & L4 & $\mathrm{L} 5$ & $\mathrm{~L} 2 / 3$ & L4 & $\mathrm{L} 5$ & $\mathrm{~L} 2 / 3$ & L4 & $\mathrm{L} 5$ & $\mathrm{~L} 2 / 3$ & L4 & $\mathrm{L} 5$ \\
\hline Sample size & 7 & 8 & 8 & 17 & 7 & 9 & 5 & 6 & 11 & 4 & 10 & 4 \\
\hline$I_{\text {holding }}(\mathrm{pA})$ & $-46.7 \pm 24.4$ & $-28.0 \pm 8.1$ & $-26.5 \pm 4.6$ & $-60.0 \pm 8.9$ & $-51.2 \pm 8.2$ & $-80.7 \pm 19.4$ & $-45.4 \pm 5.7$ & $-81.2 \pm 25.3$ & $-152.6 \pm 37$ & $-55.8 \pm 13$ & $-98.9 \pm 21.3$ & $-145.2 \pm 77$ \\
\hline$R_{\text {input }}(\mathrm{M} \Omega)$ & $428 \pm 57$ & $359 \pm 57$ & $249 \pm 53$ & $210.2 \pm 15.3$ & $230 \pm 33$ & $143 \pm 24$ & $117 \pm 13$ & $159 \pm 36$ & $113 \pm 14$ & $161 \pm 42$ & $142 \pm 16$ & $166 \pm 65$ \\
\hline$R_{\text {series }}(\mathrm{M} \Omega)$ & $16.6 \pm 0.4$ & $21.6 \pm 1.8$ & $19.1 \pm 2.3$ & $20.0 \pm 0.9$ & $22.8 \pm 1.7$ & $17.8 \pm 1.2$ & $20.7 \pm 2.4$ & $26.8 \pm 2.9$ & $20.5 \pm 1.4$ & $19.2 \pm 1.2$ & $25.8 \pm 1.8$ & $21.6 \pm 3.5$ \\
\hline $\begin{array}{l}\text { Amplitude (pA) base- } \\
\text { line }\end{array}$ & $22.3 \pm 0.8$ & $19.5 \pm 1.4$ & $17.1 \pm 1.4$ & $16.1 \pm 0.4$ & $13.1 \pm 0.8$ & $14.4 \pm 0.7$ & $14.5 \pm 1.6$ & $17.3 \pm 2.2$ & $16.1 \pm 1.2$ & $19.4 \pm 1.8$ & $12.6 \pm 0.9$ & $14.0 \pm 1.6$ \\
\hline Amplitude (pA) in APV & $21.5 \pm 0.9$ & $19.5 \pm 1.6$ & $14.7 \pm 1.0$ & $15.5 \pm 0.5$ & $12.9 \pm 0.7$ & $13.6 \pm 0.6$ & $14.4 \pm 1.3$ & $16.3 \pm 1.4$ & $15.7 \pm 1.1$ & $17.2 \pm 1.4$ & $12.2 \pm 0.7$ & $16.0 \pm 2.5$ \\
\hline $\begin{array}{l}\text { Frequency }(\mathrm{Hz}) \text { base- } \\
\text { line }\end{array}$ & $1.4 \pm 0.6$ & $1.4 \pm 0.4$ & $0.4 \pm 0.1$ & $4.0 \pm 0.6$ & $4.6 \pm 0.7$ & $3.1 \pm 0.7$ & $4.1 \pm 1.1$ & $11.4 \pm 4.2$ & $1.6 \pm 0.4$ & $4.7 \pm 2.4$ & $3.8 \pm 0.9$ & $1.9 \pm 0.6$ \\
\hline Frequency $(\mathrm{Hz})$ in APV & $1.2 \pm 0.5$ & $1.0 \pm 0.3$ & $0.3 \pm 0.1$ & $3.0 \pm 0.5$ & $3.3 \pm 0.5$ & $1.9 \pm 0.4$ & $4.1 \pm 1.0$ & $12.2 \pm 4.7$ & $1.8 \pm 0.4$ & $4.6 \pm 2.4$ & $3.6 \pm 0.9$ & $2.0 \pm 0.5$ \\
\hline$\tau_{\text {Decay }}(\mathrm{ms})$ baseline & $3.7 \pm 0.0 .3$ & $5.7 \pm 1.3$ & $5.0 \pm 0.04$ & $4.0 \pm 0.2$ & $4.5 \pm 0.2$ & $5.1 \pm 0.3$ & $4.7 \pm 0.2$ & $4.3 \pm 0.6$ & $5.8 \pm 0.3$ & $7.6 \pm 2.8$ & $5.5 \pm 0.8$ & $4.3 \pm 0.4$ \\
\hline$\tau_{\text {Decay }}(\mathrm{ms})$ in APV & $3.8 \pm 0.3$ & $5.2 \pm 0.5$ & $5.6 \pm 0.7$ & $4.3 \pm 0.1$ & $4.6 \pm 0.2$ & $5.4 \pm 0.3$ & $4.5 \pm 0.3$ & $4.7 \pm 0.6$ & $6.2 \pm 0.4$ & $7.4 \pm 2.2$ & $5.4 \pm 0.4$ & $4.5 \pm 0.6$ \\
\hline Rise time (ms) baseline & $1.0 \pm 0.1$ & $1.2 \pm 0.2$ & $1.3 \pm 0.1$ & $1.2 \pm 0.1$ & $1.4 \pm 0.1$ & $2.0 \pm 0.1$ & $1.6 \pm 0.1$ & $1.0 \pm 0.3$ & $1.6 \pm 0.1$ & $1.6 \pm 0.4$ & $1.3 \pm 0.1$ & $1.6 \pm 0.3$ \\
\hline Rise time (ms) in APV & $1.0 \pm 0.1$ & $1.3 \pm 0.2$ & $1.4 \pm 0.2$ & $1.2 \pm 0.1$ & $1.4 \pm 0.1$ & $2.1 \pm 0.2$ & $1.6 \pm 0.1$ & $1.0 \pm 0.2$ & $1.6 \pm 0.1$ & $1.6 \pm 0.5$ & $1.3 \pm 0.1$ & $1.4 \pm 0.2$ \\
\hline Area $(\mathrm{pA} \cdot \mathrm{ms})$ baseline & $69.4 \pm 5.1$ & $75.5 \pm 11.5$ & $5 \quad 61.6 \pm 6.8$ & $55.2 \pm 3.2$ & $48.4 \pm 2.9$ & $66.9 \pm 3.2$ & $56.6 \pm 8.4$ & $47.4 \pm 8.5$ & $71.2 \pm 5.5$ & $81.1 \pm 23.1$ & $140.8 \pm 3.8$ & $54.5 \pm 5.0$ \\
\hline Area $(p A \cdot m s)$ in APV & $67.2 \pm 5.2$ & $77.3 \pm 13.6$ & $6 \quad 56.0 \pm 5.4$ & $51.9 \pm 3.2$ & $46.8 \pm 2.9$ & $64.9 \pm 3.6$ & $55.6 \pm 6.1$ & $45.3 \pm 6.7$ & $69.5 \pm 4.9$ & $72.4 \pm 20.2$ & $239.2 \pm 3.2$ & $60.1 \pm 4.2$ \\
\hline
\end{tabular}

\section{Results \\ Postsynaptic hyperpolarization or MK-801 blocks postsynaptic NMDARs}

To probe for the presence of functional presynaptic NMDARs in visual cortical pyramidal cells, we used established protocols in slices from mice aged P7-P90 (Berretta and Jones, 1996; Sjöström et al., 2003; Bender et al., 2006a; Yang et al., 2006). In one strategy, postsynaptic NMDARs are first blocked with strong hyperpolarization. Then, the subsequent effects of bath applying the NMDAR antagonist APV $(100 \mu \mathrm{M})$ are measured to reveal the effect that the remaining, presumably presynaptic, NMDARs have on spontaneous neurotransmitter release (Fig. 1A). To validate this approach, we first pharmacologically isolated NMDAR-mediated EPSCs and examined the $I-V$ relationship at the $\mathrm{L} 4 \rightarrow \mathrm{L} 2 / 3$ synapse. L4 stimulation was adjusted to evoke $\sim 100 \mathrm{pA}$ response at $+24 \mathrm{mV}$. The synaptically evoked NMDAR currents exhibited strong rectification generated from $\mathrm{Mg}^{2+}$ block (Mayer et al., 1984; Nowak et al., 1984), showing that $<4 \%$ of the current remained at $-80 \mathrm{mV}$ compared with what would be expected from a linear $I-V$ relationship (Fig. $1 B$ ). Although strong hyperpolarization clearly blocks evoked NMDAR currents, we also wanted to verify that it blocked NMDAR currents driven by spontaneous neurotransmitter release. Our findings demonstrate that APV has no effect on the amplitude or kinetics of mEPSCs recorded at $-80 \mathrm{mV}$ in the presence of TTX (200 nM) (Fig. 1C), suggesting that the NMDAR component of the mEPSCs was either absent or so small that it was below the detection level. To demonstrate that functional postsynaptic NMDARs can be detected in mEPSC recordings in the absence of $\mathrm{Mg}^{2+}$ block, we showed that APV blocked a long-duration current recorded at $-60 \mathrm{mV}$ in low $\mathrm{Mg}^{2+}(0.1 \mathrm{~mm})$ (Fig. 1C). These observations demonstrate that hyperpolarization is an effective means for blocking postsynaptic NMDAR currents.

Postsynaptic NMDARs can also be blocked by including $0.5-1$ $\mathrm{mM}$ MK-801 in the postsynaptic recording pipette (iMK-801) (Berretta and Jones, 1996; Bender et al., 2006b; Yang et al., 2006). Notably, the postsynaptic block of NMDARs with iMK-801 does not act by spillover into the extracellular medium (Bender et al., 2006b) (see Fig. 5). By examining the input output (I-O) relationship of $\mathrm{L} 2 / 3$ cells recorded at $+24 \mathrm{mV}$ with and without iMK-801, we demonstrate that iMK- 801 blocks $>96 \%$ of the NMDAR current evoked at $20 \mu \mathrm{A}$, which was our average stimulation intensity for additional experiments using this technique.
On average we evoked $38 \pm 12.8$ pA NMDAR responses under control conditions $(n=6)$ but only $1.4 \pm 1.8 \mathrm{pA}$ responses with iMK-801 $(n=7 ; p=0.0076)$, similar to the $>90 \%$ block of NMDAR currents that has been observed previously using iMK801 (Berretta and Jones, 1996; Bender et al., 2006b). Importantly, iMK-801 was even more effective at eliminating postsynaptic NMDAR currents at holding potentials near rest (Fig. $1 E$ ). With iMK-801 and using a stimulation intensity of $30 \mu \mathrm{A}$, the NMDAR current measured at $-65 \mathrm{mV}$ is completely blocked ( $0.22 \pm 5.42$ $\mathrm{pA} ; n=4)$ compared with control $(-35.13 \pm 22.78 \mathrm{pA} ; n=5)$.

\section{Presynaptic NMDARs facilitate spontaneous neurotransmitter release in the visual cortex of young mice ( $<$ P20) but not older mice $(>$ P23)}

To probe for functional presynaptic NMDARs in L2/3 at P16, we first blocked postsynaptic NMDARs with hyperpolarization to $-80 \mathrm{mV}$. We then measured the effects of bath applying APV on the frequency and amplitude of mEPSCs recorded in TTX. Miniature EPSCs arise from spontaneous neurotransmitter release, and their frequency typically depends on presynaptic properties, whereas their amplitude depends on postsynaptic properties. Under these conditions, APV reversibly attenuated the frequency of mEPSCs in L2/3 pyramidal cells (Fig. $2 A-C)(p=0.002$, Kruskal-Wallis test), without affecting their amplitude or kinetics (Figs. 1C, 2C). Notably, control cells recorded for the same duration, but without APV application, showed no change in mEPSC frequency or amplitude (Fig. $2 D$ ). In a subset of experiments, D-APV was used to confirm that the decrease in frequency was caused by a block of NMDARs and not a nonspecific effect of L-APV on metabotropic glutamate receptors (Thoreson and Ulphani, 1995; Lieske and Ramirez, 2006). Together, these observations indicate that presynaptic NMDARs tonically enhance the frequency of spontaneous release in young animals.

The observation of presynaptic NMDARs in L2/3 visual cortex of young mice prompted us to establish whether there are laminar or developmental differences in their function. We assayed presynaptic NMDARs in four age groups: before eye opening (P7-P11), after eye opening (P13-P20), during the peak of the critical period for ocular dominance plasticity (P23-P30) (Gordon and Stryker, 1996), and in adulthood (P72-P90). We found that the reduction in mEPSC frequency by APV was not limited to $\mathrm{L} 2 / 3$ at P16, because APV similarly reduced mEPSC frequency in $\mathrm{L} 2 / 3, \mathrm{~L} 4$, and $\mathrm{L} 5$ in mice from P7-P11 and P13-P20 (Fig. 3A, 
Table 1) ( $p$ values $<0.0045$, paired $t$ tests with a Bonferroni correction). However, there was a striking absence of an effect by APV in L2/3, L4, and L5 in older mice (P23-P30 and P72-P90) (Fig. 3A, Table 1) ( $p$ values $>0.05$ ), arguing that functional presynaptic NMDARs are lost. Several lines of evidence indicate that the reduction in mEPSC frequency in young mice was caused by a presynaptic change in neurotransmitter release and was not mediated by a postsynaptic mechanism (e.g., rundown or reduced postsynaptic AMPA receptor number). (1) The reduction in mEPSC frequency by APV was reversible (Figs. $2 B, 3 B$ ) (frequency in $\mathrm{D}$-APV or APV $=75.3 \pm 5.0 \%$ of baseline; $p=0.0003$; frequency after APV washout $=99.6 \pm 5.0 \%$ of baseline; $p=$ $0.93 ; n=15)$. (2) We did not observe a significant reduction in mEPSC frequency in control cells that were recorded for a similar duration (Fig. 3B). (3) There was no significant change in mEPSC amplitude or kinetics by APV application in all lamina at all ages studied (Figs. 2D, 3C,D; Table 1). Collectively, our data show that there is a developmental loss in the ability of presynaptic NMDARs to facilitate neurotransmitter release in the visual cortex. This might partially explain previous observations in cats that the NMDAR contribution to visual responses diminishes around critical period onset, at least in layers 4 and 5 (Fox et al., 1989).

\section{The developmental loss of presynaptic NMDAR function is coincident with a reduction in the prevalence of presynaptic NMDARs}

One parsimonious explanation for the developmental loss of presynaptic NMDAR function is that fewer synapses contain presynaptic NMDARs in older mice. To test this, we used EM to examine the presynaptic and postsynaptic prevalence of asymmetric (excitatory) synapses in L2/3 containing the NR1 subunit, which is obligatory for NMDAR function (Fig. 4). We examined a total of 1073 synapses from two brains each at P16 and P27 (Table 2). Although the percentage of synapses containing NR1 at the postsynaptic density was similar in P16 and P27 brains (77 and $75 \%$ at $\mathrm{P} 16 ; 84$ and $75 \%$ at $\mathrm{P} 27$ ), there was a $50 \%$ developmental reduction in NR1 at presynaptic sites (Fig. $4 E$ ). Specifically, a majority $(>60 \%)$ of presynaptic terminals contained NR1 in each of two brains at P16 ( $n=240$ and 420 synapses examined), whereas $<30 \%$ of the presynaptic sites were labeled in two P27 brains ( $n=254$ and 159 synapses examined). Postsynaptic NR1, however, was $>75 \%$ at both ages, revealing an $\sim 50 \%$ developmental reduction in the ratio of presynaptic versus postsynaptic localization of NR1 (Table 2). It is unlikely that age-dependent differences in the quality of either the perfusions or antibody penetration into the tissue confounded this analysis, because presynaptic and postsynaptic profiles in each brain shared the same factors that may influence the outcomes of the immunocytochemistry (such as caliber of presynaptic and postsynaptic profiles, size of extracellular space, and astrocytic processes). Similarly, it is unlikely that the reduction in presynaptic NR1 prevalence is a consequence of reduced antibody penetration and generally light presynaptic labeling, combined. This is because it is in fact easier to detect DAB label in a terminal than in a postsynaptic profile, because of the presence of gray postsynaptic density in the latter. The observation that the prevalence of postsynaptic NR1 was unchanged during development suggests that no drastic changes have occurred in immunolabeling quality between the two ages examined. Thus, the anatomical reduction in presynaptic NMDARs correlates with our physiological data demonstrating a dramatic developmental loss of functional presynaptic NMDARs over this time course, suggestive of a causal relationship.
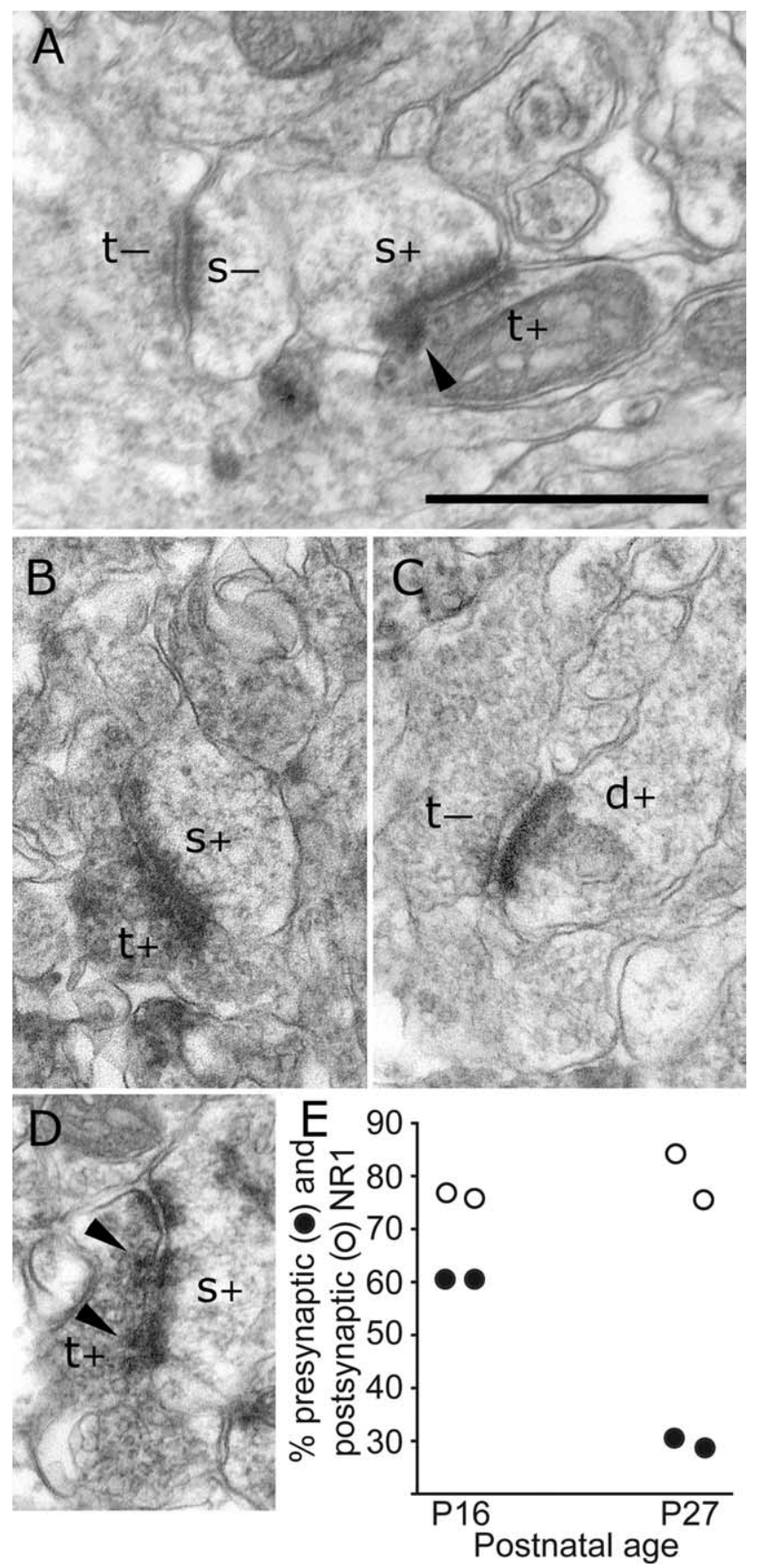

Figure 4. The presence of presynaptic NR1 is downregulated with development. $A$, Electron micrograph in visual cortex L2/3 of a P16 mouse demonstrating an NR1-positive terminal $(t+)$ making a synapse with a spine that is also NR1 positive $(s+)$. An NR1-negative presynaptic terminal ( $\mathrm{t}-$ ) making an asymmetric synapse onto an NR1-negative spine $(\mathrm{s}-)$ is present in the same field. Scale bar: $\boldsymbol{A}-\boldsymbol{D}, 250 \mathrm{~nm}$. Arrowheads highlight aggregations of DAB in presynaptic terminals. $\boldsymbol{B}$, In a section from L2/3 of another P16 mouse, a diffusely labeled terminal $(\mathrm{t}+)$ is seen forming a synapse onto a spine $(\mathrm{s}+)$ that contains NR1 label at the postsynaptic density. C, At P27, most synapses exhibit postsynaptic, but not presynaptic, NR1. An unlabeled terminal $(t-)$ forms a synapse onto a labeled dendrite $(d+)$. D, In a section from another P27 mouse, an NR1-positive terminal ( $t+)$ makes a synapse onto an NR1-positive spine $(s+) . \boldsymbol{E}$, Scatter plot from four mice (2 at each age) quantifying the selective loss of presynaptic, but not postsynaptic, NR1 over development. Note that $30 \%$ of terminals still contain NR1 at P27.

\section{Developmental switch in the role of presynaptic and postsynaptic NMDARs in tLTD}

What is the functional significance of this developmental loss of presynaptic NMDARs to synaptic plasticity during development? 
Table 2. Data for immuno-EM labeling of NR1

\begin{tabular}{|c|c|c|c|c|c|c|c|c|}
\hline Animal \# & Age & $\begin{array}{l}\text { Number of } \\
\text { synaptic terminals } \\
\text { examined }\end{array}$ & $\begin{array}{l}\text { Number of } \\
\text { synapses with } \\
\text { presynaptic NR1 }\end{array}$ & $\begin{array}{l}\text { Number of } \\
\text { unlabeled } \\
\text { presynaptic terminals }\end{array}$ & $\begin{array}{l}\text { Number of } \\
\text { synapses with NR1 } \\
\text { at the postsynaptic } \\
\text { density }\end{array}$ & $\begin{array}{l}\text { Percentage of } \\
\text { synapses with NR1 } \\
\text { at the presynaptic } \\
\text { terminal }\end{array}$ & $\begin{array}{l}\text { Percentage of } \\
\text { synapses with NR1 } \\
\text { at the postsynaptic } \\
\text { density }\end{array}$ & $\begin{array}{l}\text { Ratio of presynaptic/ } \\
\text { postsynaptic NR1 } \\
\text { labeling }\end{array}$ \\
\hline 1 & P16 & 240 & 145 & 95 & 185 & 60.42 & 77.08 & 0.7838 \\
\hline 2 & P16 & 420 & 254 & 166 & 319 & 60.48 & 75.95 & 0.7962 \\
\hline 3 & P27 & 254 & 78 & 176 & 214 & 30.71 & 84.25 & 0.3644 \\
\hline 4 & P27 & 159 & 46 & 113 & 120 & 28.93 & 75.47 & 0.3833 \\
\hline
\end{tabular}

A

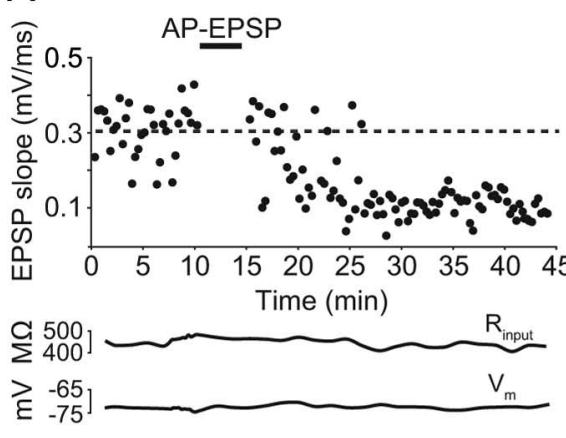

C

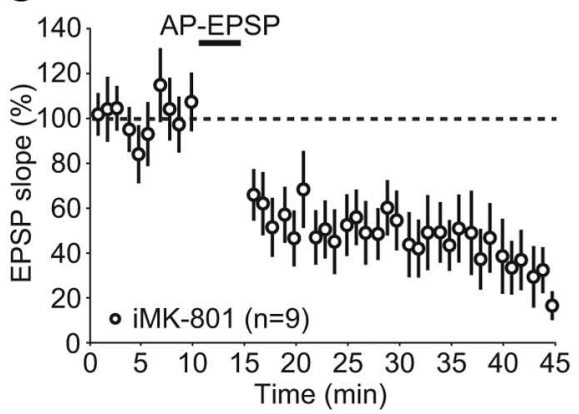

B

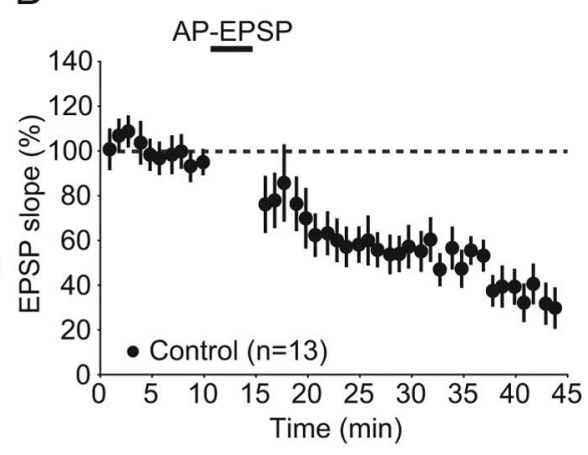

D

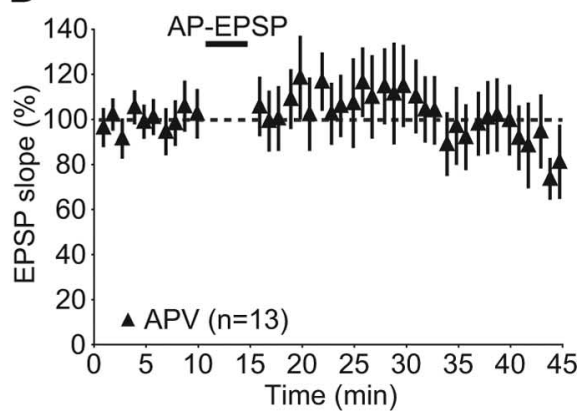

Figure 5. Presynaptic NMDARs are required for $\mathrm{LTD}$ at $\mathrm{L} 4 \rightarrow \mathrm{L} 2 / 3$ synapses in young $(<\mathrm{P} 20)$ mice. $A$, Example of tLTD induced at $\mathrm{L} 4 \rightarrow \mathrm{L} 2 / 3$ synapses by AP-EPSP pairings in a $\mathrm{P} 13$ mouse. $R_{\text {input }}$ and $V_{\mathrm{m}}$ do not change significantly over the time course of the experiment. $\boldsymbol{B}$, Averaged data from control cells demonstrating the depression in EPSP slope $(p<0.007)$ induced with AP-EPSP pairings. C, Strong tLTD could be induced with AP-EPSP pairings even when postsynaptic NMDARs were blocked by inclusion of MK-801 in the internal recording solution (iMK-801) $(p<0.018)$. This suggests that postsynaptic NMDARs are not required for tLTD induction in these young mice. $\boldsymbol{D}$, Induction of tLTD was prevented by bath application of the NMDAR antagonist APV ( $p>$ 0.798), arguing that presynaptic NMDARs are required for the induction of tLTD.

Presynaptic NMDARs in young rodents have been implicated in tLTD (Sjöström et al., 2003; Bender et al., 2006b), a form of synaptic plasticity thought to be important for the acquisition of receptive field properties (Dan and Poo, 2006). Thus, we predicted that either the developmental loss of presynaptic NMDARs in L2/3 would abolish the ability to induce tLTD or there would be a different induction mechanism for tLTD later in development. To test these possibilities, we used a standard tLTD protocol by repeatedly pairing a postsynaptic AP in an L2/3 pyramidal cell closely followed (5-25 ms) by an EPSP evoked by L4 stimulation. In young mice (P13-P17), AP-EPSP pairings produced strong tLTD (Fig. $5 A, B)(43.6 \pm 5.6 \%$ of baseline slope; $n=13 ; p<0.007)$. Similarly, robust tLTD could be induced when the NMDAR antagonist MK-801 was included in the recording electrode (iMK-801) to block postsynaptic NMDARs (Berretta and Jones, 1996; Bender et al., 2006b) (Fig. 5C) (36.2 \pm $9.1 \%$ of baseline; $n=9 ; p=0.017)$. However, bath application of APV prevented induction of tLTD in young mice (Fig. $5 D$ ) (95.3 $\pm 9.0 \%$ of baseline; $n=13 ; p=0.80$ ), suggesting that the synaptic weakening relied on activation of presynaptic and not postsynaptic NMDARs. The absence of LTD in the presence of bath APV could be attributable to either a direct block of LTD induction or to an occlusion of LTD from an APVmediated suppression of neurotransmission (Sjöström et al., 2003; Bender et al., 2006b). Either way, the block by APV demonstrates an important role for presynaptic NMDARs in tLTD induction. Notably, the iMK-801 experiments also serve as an additional control showing that iMK-801 is not acting by spillover into the extrasynaptic medium; otherwise, iMK801 would have blocked tLTD in a manner similar to APV.

To determine whether the tLTD in young mice was expressed as a presynaptic reduction in neurotransmitter release, we analyzed synaptic depression in a highfrequency stimulus train of six pulses at 30 $\mathrm{Hz}$ before and after tLTD induction. The STD index was used as a measure of changes in synaptic depression (see Materials and Methods). In the STD index, a negative number indicates that a manipulation reduces the rate of short-term depression. Because higher rates of shortterm depression are generally associated with a higher initial probability of neurotransmitter release, a negative STD index indicates that a manipulation is likely to have lowered the probability of neurotransmitter release. By analyzing the STD index on the same cells shown in Figure 5, we observed that the rate of synaptic depression during stimulation was reduced after AP-EPSP pairings under control conditions (Fig. $6 A, B$ ) (STD index $=-0.30 \pm 0.11$; $n=13)$ and when the recording electrode contained MK-801 (Fig. 6C) (STD index $=-0.24 \pm 0.09 ; n=9)$. One control cell was excluded from LTD and STD analysis for technical and statistical reasons. Technically, the magnitude of LTD in this particular cell was so large that we were unable to detect an EPSP above noise level. Statistically, the data point failed the Grubb's outlier test when we tried to analyze it to the best of our abilities. When AP-EPSP pairings were made during the bath application of APV to block all NMDARs, there was no change in the STD index (Fig. $6 D)($ STD index $=-0.005 \pm 0.09 ; n=13)$. The STD index under conditions in which tLTD was successfully induced (control and iMK-801 groups) was significantly different from bath APV experiments in which tLTD was not induced $(p<0.03)$. Therefore, in young mice, we conclude that the induction of tLTD in L2/3 
requires the activation of presynaptic NMDARs, and this tLTD is expressed as a reduction in the probability of neurotransmitter release.

In contrast to the failure of $\mathrm{MMK}-801$ to block tLTD in younger mice, postsynaptic blockade of NMDARs with iMK-801 in older mice (P23-P30) prevented the induction of tLTD in L2/3 pyramidal cells (Fig. $7 C)(n=7 ; p=0.79)$. Notably, in control conditions, AP-EPSP pairings significantly reduced synaptic strength in the visual cortex of these older mice (Fig. 7 $A, B$ ) $(67.7 \pm 7.0 \%$ of baseline; $n=5 ; p=0.018)$. Collectively, these data demonstrate that tLTD can be induced in the $\mathrm{L} 4 \rightarrow \mathrm{L} 2 / 3$ pathway in the visual cortex of mice aged P23$\mathrm{P} 30$, but the induction at this older age requires postsynaptic NMDARs. These results, however, do not rule out the possibility that presynaptic NMDARs also contribute to tLTD at this older age. Our observations that postsynaptic NMDARs are required for tLTD induction in critical period mice is consistent with a previous study using a low-frequency pairing protocol to induce LTD at this age (Crozier et al., 2007). Notably, that study also demonstrated that timing-dependent LTD in younger mice did not require postsynaptic NMDARs, and our data suggest that the differential involvement of postsynaptic NMDARs in LTD is likely caused by age rather than induction protocol.

Interestingly, we found a developmental shift in the capacity for tLTD induction that depended on the presence of intact inhibition in the slice. We found that, in P13-P20 animals, the magnitude of tLTD was similar in the presence or absence of picrotoxin to block inhibition. Because the amount and quality of the tLTD did not differ between the two conditions in this young age group, these data were combined. In the older group, however, we found that tLTD could not be induced in the absence of picrotoxin (Fig. 7D) (95.7 \pm $21.0 \%$ of baseline; $n=8 ; p=0.30$ ). The basis for this effect is currently unknown, but it could be a consequence of the maturation of inhibition at critical period onset (Katagiri et al., 2007) and/or the onset of a shunting inhibition (Hirsch, 1995).

To determine whether the tLTD in older mice was also expressed as a presynaptic reduction in neurotransmitter release, we analyzed the STD index and observed that the rate of synaptic depression during stimulation was decreased after AP-EPSP pairings under control conditions (Fig. 8) (STD index $=-0.72 \pm 0.42$; $n=11)$. Therefore, in older mice, although the induction of tLTD in L2/3 re-
A

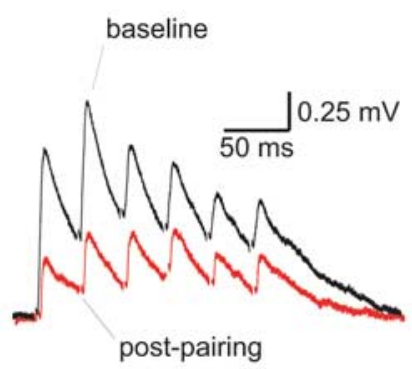

C

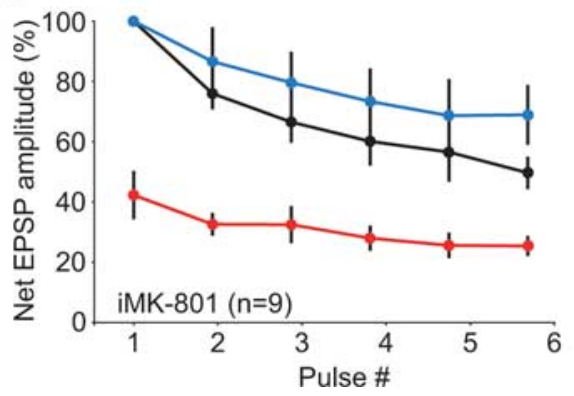

B •baseline

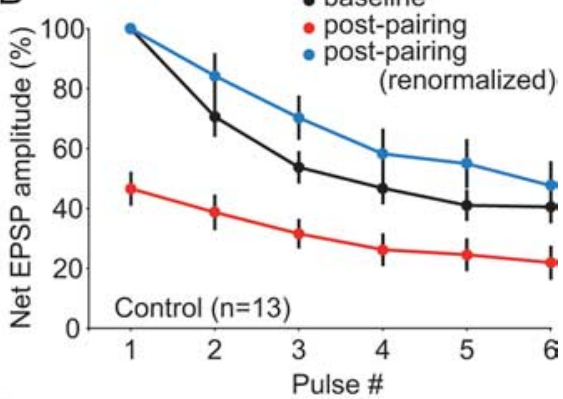

D

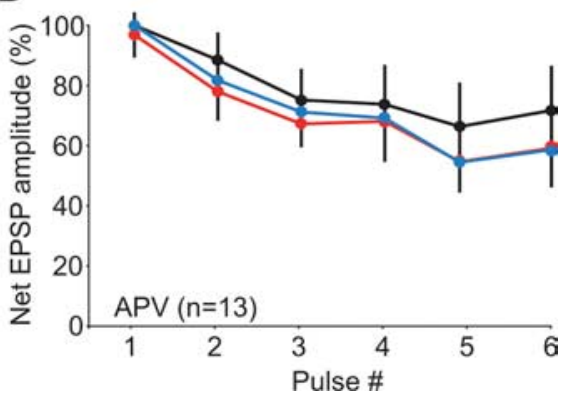

Figure 6. Analysis of synaptic depression indicates that tLTD induction in P13-P17 mice is expressed as a decrease in release probability. $\boldsymbol{A}$, Sample waveform of six pulses evoked by $30 \mathrm{~Hz}$ stimulation before and after AP-EPSP pairings. This example recording was made with iMK-801. $\boldsymbol{B}$, In the control conditions, the rate of synaptic depression at $L 4 \rightarrow L 2 / 3$ connections was reduced after tLTD produced by AP-EPSP pairings. This suggests that the pairing protocol caused a lasting reduction in neurotransmitter release. The STD index was used here as a measure of synaptic depression (see Materials and Methods). C, AP-EPSP pairing induction of tLTD made with iMK-801 also produced a reduction in the rate of synaptic depression, indicating that the pairing-induced reduction in neurotransmitter release did not require activation of postsynaptic NMDARs. $\boldsymbol{D}$, There was no significant change in synaptic depression when tLTD is blocked by bath application of APV, suggesting a role for presynaptic NMDARs in the tLTD. Data are from the same cells as in Figure 5.
A

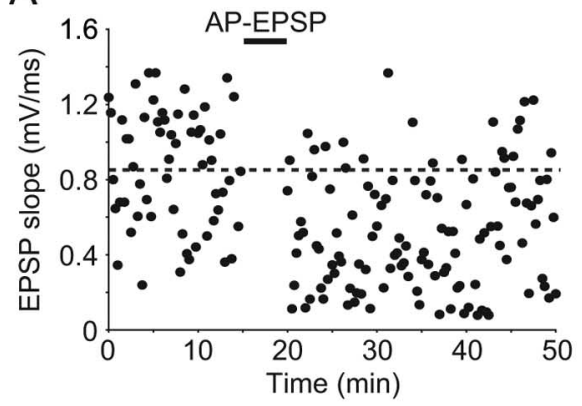

C

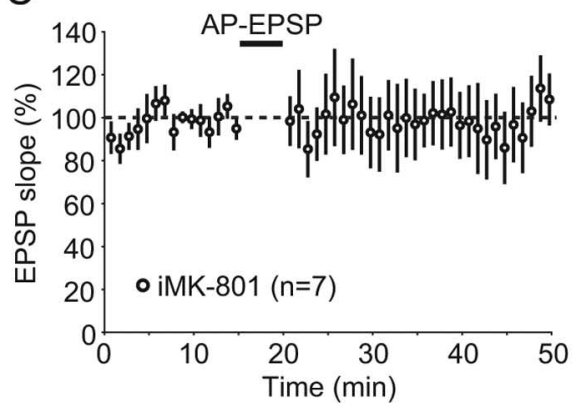

B

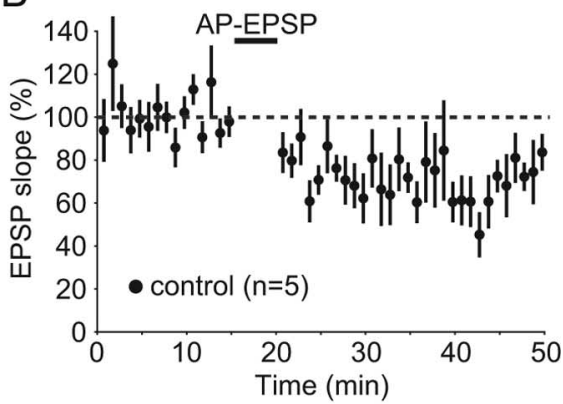

$\mathrm{D}$

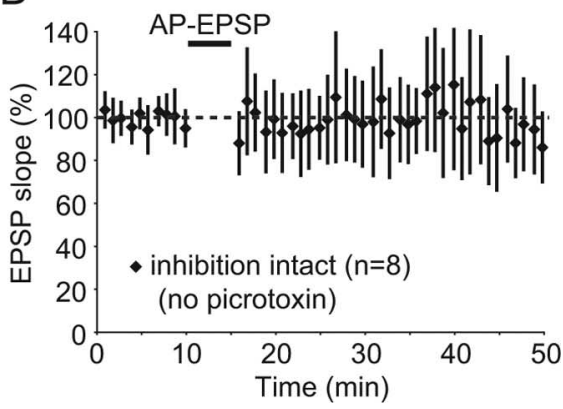

Figure 7. Postsynaptic NMDARs are required for tLTD induction in critical period mice (P23-P30). $\boldsymbol{A}$, Example of tLTD induced at L4 $\rightarrow$ L2/3 synapses by AP-EPSP pairings in a P27 mouse. $B$, In P23-P30 mice, AP-EPSP pairings induced a small degree of tLTD $(p=0.02)$. C, No tLTD was induced when postsynaptic NMDARs were blocked by iMK-801 $(p>0.79)$, suggesting that the activation of postsynaptic NMDARs is required for the full expression of the long-term depression. $D$, No tLTD was induced when inhibition was left intact (no picrotoxin in the bath ACSF) $(p=0.30)$. 
A

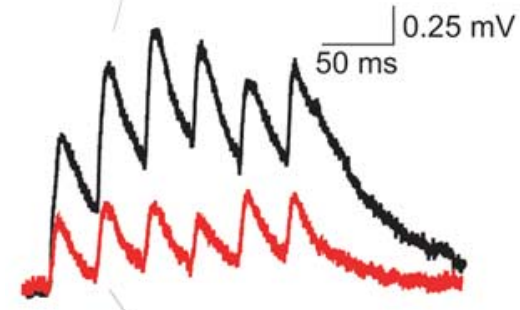

post-pairing

\section{$\mathrm{B}$}

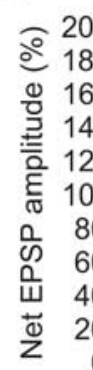

- baseline

- post-pairing

- post-pairing (renormalized)

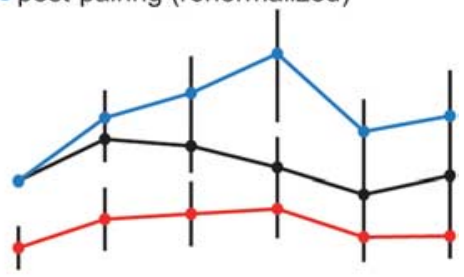

Control $(n=11)$
12

Figure 8. Analysis of synaptic depression indicates that tLTD induction in P26-P28 mice can be expressed as a decrease in release probability. $\boldsymbol{A}$, Sample waveform of six pulses evoked by $30 \mathrm{~Hz}$ stimulation before and after AP-EPSP pairings. $\boldsymbol{B}$, The rate of synaptic depression at $L 4 \rightarrow L 2 / 3$ connections was reduced after tLTD produced by AP-EPSP pairings.

quires the activation of postsynaptic NMDARs, it is expressed, at least in part, by a decrease in neurotransmitter release. Although a change in STD index after tLTD induction suggests a presynaptic tLTD expression mechanism, we cannot rule out the possibility that the tLTD is being simultaneously expressed postsynaptically (Lisman and Raghavachari, 2006).

\section{Discussion}

A vast area of neuroscience research is dedicated to the study of NMDAR-mediated synaptic plasticity (Malenka and Bear, 2004). To date, most research has concentrated on postsynaptic NMDARs, whereas the role and even the very existence of presynaptic NMDARs have been controversial or largely ignored. However, presynaptic NMDARs are important to consider, because studies in different cell types, pathways, brain regions, species, and ages have found varying degrees of involvement of presynaptic and postsynaptic NMDARs in synaptic plasticity (Sjöström et al., 2003; Malenka and Bear, 2004; Froemke et al., 2005; Bender et al., 2006b; Duguid and Sjöström, 2006). Our study focused on the function of presynaptic NMDARs and their putative role in LTD, specifically within the developing mouse visual cortex. Consistent with observations in other cortical layers and other regions of the brain (Sjöström et al., 2003; Malenka and Bear, 2004; Froemke et al., 2005; Bender et al., 2006b; Duguid and Sjöström, 2006), we demonstrate that presynaptic NMDARs are present and contribute to the spike timing-dependent induction of LTD in neocortical L2/3 of young animals. This tLTD is expressed, at least in part, as a presynaptic reduction in neurotransmitter release. We also provide three key findings demonstrating that the role of presynaptic NMDARs in synaptic transmission and plasticity is highly age dependent. (1) The tonic function of presynaptic NMDARs is lost in development, at least in the assays used here. (2) There is a developmental reduction in the prevalence of presynaptic terminals containing the obligatory NR1 subunit. (3) The developmental reduction of presynaptic NMDARs may be compensated for by the emergence of a postsynaptic role for NMDARs in the induction of tLTD. Our data thus highlight the changing functions of presynaptic NMDARs over development and provide the first evidence for a developmental switch in the involvement of NMDARs in timingdependent plasticity.

The loss of functional presynaptic NMDARs has a clear mechanistic importance for the induction of tLTD, but what is the cellular basis for this loss? An obvious possibility, which we tested, is that the prevalence of presynaptic NMDARs decreases with development. Here we show the first anatomical data to indicate both that NMDARs are present presynaptically at the majority of excitatory synapses in L2/3 early in development (P16) and that their prevalence is reduced by $50 \%$ over the next $10 \mathrm{~d}$. The developmental decrease in presynaptic NMDAR prevalence correlates temporally with a loss in their contribution to neurotransmitter release, suggesting a causal relationship. However, there may be additional contributing factors to the loss of presynaptic NMDAR function, because our anatomical data also indicate that presynaptic NMDARs remain at $\sim 30 \%$ of the synapses even when we no longer observe their effect on mEPSC frequency. At least five possibilities exist for why we observe a complete loss of functional presynaptic NMDARs in these older mice despite our anatomical evidence that presynaptic NMDARs remain at a small subset of synapses. First, the number of NMDARs remaining at individual boutons may be below a threshold needed to have a measurable impact on neurotransmitter release. Second, presynaptic NMDARs may undergo a developmental change in their subunit composition rendering them less effective. Because functional presynaptic NMDARs in both the visual cortex (Sjöström et al., 2003) and the entorhinal cortex (Woodhall et al., 2001) are thought to contain NR2B subunits, the developmental increase in the relative expression of NR2A to NR2B NMDAR subunits in the visual cortex (Nase et al., 1999; Quinlan et al., 1999a,b) may contribute to the loss of presynaptic NMDAR function. Third, the inputs that maintain presynaptic NMDARs later in development may not participate in the spontaneous release of neurotransmitter. Fourth, presynaptic NMDARs may become functionally uncoupled during development from the neurotransmitter release machinery. A final possibility is that the remaining presynaptic NMDARs may lose their efficacy because of a developmental reduction in a cofactor that is necessary for them to exert their influences. Although we did not observe a functional role for presynaptic NMDARs at later stages of development, an adult functionality for presynaptic NMDARs may become apparent in assays other than the ones used in this study.

Our data add to recent literature suggesting that presynaptic NMDARs are regulated in a developmental- and activitydependent manner (Mameli et al., 2005; Yang et al., 2006). For example, the neurosteroid pregnenolone increases the probability of glutamate release through presynaptic NMDARs in the $\mathrm{CA} 3 \rightarrow \mathrm{CA} 1$ hippocampal synapse, and this effect is thought to be lost at P5 as a result of a decrease in NR2D-containing NMDARs (Mameli et al., 2005). A similar but much more gradual reduction in presynaptic NMDAR function occurs in layer 5 of the rat entorhinal cortex, where their function is pronounced at $\sim 5$ weeks of age and only modest at $\sim 5$ months of age (Yang et al., 2006). Notably, in the entorhinal cortex, presynaptic NMDAR function can also be regulated in an activity-dependent manner, as the induction of seizures in adults restores juvenile levels of presynaptic NMDAR function (Yang et al., 2006). The combined data demonstrate that presynaptic NMDAR function can be bidirectionally regulated to alter neurotransmitter release. The developmental loss of presynaptic NMDARs may be a general feature of neural development, and the time course for this loss could be highly dependent on brain region. We also stress that the present 
study was performed in mice and that there may be important differences between species. Additional studies are needed to explore these possibilities.

Why would the ability of presynaptic NMDARs to enhance neurotransmitter release diminish with development? We suggest that presynaptic NMDARs may be needed to support high neurotransmitter release probabilities. This idea is consistent with the general observations that the probability of neurotransmitter release is much greater early in development, when presynaptic NMDARs are presumably present, than at later stages of development, when they are more likely to be absent (Bolshakov and Siegelbaum, 1995; Choi and Lovinger, 1997; Reyes and Sakmann, 1999; Silver et al., 2003; Volgushev et al., 2004). A high probability of neurotransmitter release in immature synapses may be needed for terminals to make their initial postsynaptic connections and to maintain neurotransmission when postsynaptic receptors are fewer in number (Rumpel et al., 2004). The developmental loss of the ability of presynaptic NMDARs to support neurotransmitter release may also help explain the general observation that synapses switch from depressing to facilitating during development in many brain regions (Pouzat and Hestrin, 1997; Reyes and Sakmann, 1999).

Presynaptic NMDARs can be activated from evoked glutamate release, but our study and others demonstrate that they can also be activated tonically. This suggests that the receptors are activated by ambient levels of glutamate. Indeed, low levels of ambient glutamate have been observed (Meldrum, 2000). In vitro, not only can ambient glutamate tonically activate NMDARs (Sah et al., 1989), but ambient glutamate can also activate kainate receptors (Lauri et al., 2006) and metabotropic glutamate receptors (Bandrowski et al., 2003). Interestingly, glia have recently been shown to provide a major source of ambient and evoked glutamate (Jourdain et al., 2007; Le Meur et al., 2007). Notably, the NMDAR glycine binding sites on presynaptic NMDARs appear to be saturated, unlike postsynaptic NMDARs, suggesting that presynaptic NMDARs are primed to be activated by glutamate (Li and Han, 2007). Currently it is unknown whether presynaptic NMDARs require depolarization for their activation. Because of the high input resistance of presynaptic terminals, even modest excitatory currents locally at terminals might be sufficient to cause depolarization-induced removal of $\mathrm{Mg}^{2+}$ from NMDARs (Jourdain et al., 2007). Another possibility is that presynaptic NMDARs may not require depolarization to be activated; presynaptic NMDARs containing NR2C, NR2D, or NR3A all show less voltage sensitivity than other NMDAR subtypes (Monyer et al., 1992; Cull-Candy et al., 2001; Sasaki et al., 2002).

A common theme appears to be emerging that the induction mechanisms of synaptic plasticity adjust over development to adapt to ongoing changes in presynaptic and postsynaptic properties (Yasuda et al., 2003; Frenkel and Bear, 2004; Nosyreva and Huber, 2005; Yashiro et al., 2005; He et al., 2006; Jo et al., 2006). For example, there is a developmental switch in the relative presynaptic versus postsynaptic expression of metabotropic glutamate receptor-mediated LTD in the hippocampus (Nosyreva and Huber, 2005). Thus, our findings add to a growing body of literature that the properties of synaptic plasticity must be studied within a developmental context. Our data also raise the exciting possibility that presynaptic NMDARs might regulate plasticity during a precritical period early in development but that postsynaptic NMDARs may be more critically involved in experiencedependent synaptic plasticity later in development. Given the observations that presynaptic NMDARs exist early in development in the hippocampus (Mameli et al., 2005), entorhinal cor- tex (Yang et al., 2006), and visual cortex (present study) but not at later stages of maturation, we suggest that the development loss of presynaptic NMDAR function may be an important and general property of early circuit formation.

\section{References}

Aoki C, Venkatesan C, Go CG, Mong JA, Dawson TM (1994) Cellular and subcellular localization of NMDA-R1 subunit immunoreactivity in the visual cortex of adult and neonatal rats. J Neurosci 14:5202-5222.

Bandrowski AE, Huguenard JR, Prince DA (2003) Baseline glutamate levels affect group I and II mGluRs in layer $\mathrm{V}$ pyramidal neurons of rat sensorimotor cortex. J Neurophysiol 89:1308-1316.

Bardoni R, Torsney C, Tong CK, Prandini M, MacDermott AB (2004) Presynaptic NMDA receptors modulate glutamate release from primary sensory neurons in rat spinal cord dorsal horn. J Neurosci 24:2774-2781.

Bear MF, Rittenhouse CD (1999) Molecular basis for induction of ocular dominance plasticity. J Neurobiol 41:83-91.

Bender KJ, Allen CB, Bender VA, Feldman DE (2006a) Synaptic basis for whisker deprivation-induced synaptic depression in rat somatosensory cortex. J Neurosci 26:4155-4165.

Bender VA, Bender KJ, Brasier DJ, Feldman DE (2006b) Two coincidence detectors for spike timing-dependent plasticity in somatosensory cortex. J Neurosci 26:4166-4177.

Berardi N, Pizzorusso T, Maffei L (2000) Critical periods during sensory development. Curr Opin Neurobiol 10:138-145.

Berretta N, Jones RS (1996) Tonic facilitation of glutamate release by presynaptic $N$-methyl-D-aspartate autoreceptors in the entorhinal cortex. Neuroscience 75:339-344.

Bolshakov VY, Siegelbaum SA (1995) Regulation of hippocampal transmitter release during development and long-term potentiation. Science 269:1730-1734.

Burkhalter A (1989) Intrinsic connections of rat primary visual cortex: laminar organization of axonal projections. J Comp Neurol 279:171-186.

Casado M, Isope P, Ascher P (2002) Involvement of presynaptic $N$-methylD-aspartate receptors in cerebellar long-term depression. Neuron 33:123-130.

Charton JP, Herkert M, Becker CM, Schroder H (1999) Cellular and subcellular localization of the $2 \mathrm{~B}$-subunit of the NMDA receptor in the adult rat telencephalon. Brain Res 816:609-617.

Choi S, Lovinger DM (1997) Decreased probability of neurotransmitter release underlies striatal long-term depression and postnatal development of corticostriatal synapses. Proc Natl Acad Sci USA 94:2665-2670.

Clements JD, Bekkers JM (1997) Detection of spontaneous synaptic events with an optimally scaled template. Biophys J 73:220-229.

Crowley JC, Katz LC (1999) Development of ocular dominance columns in the absence of retinal input. Nat Neurosci 2:1125-1130.

Crozier RA, Wang Y, Liu CH, Bear MF (2007) Deprivation-induced synaptic depression by distinct mechanisms in different layers of mouse visual cortex. Proc Natl Acad Sci USA 104:1383-1388.

Cull-Candy S, Brickley S, Farrant M (2001) NMDA receptor subunits: diversity, development and disease. Curr Opin Neurobiol 11:327-335.

Dan Y, Poo MM (2006) Spike timing-dependent plasticity: from synapse to perception. Physiol Rev 86:1033-1048.

Duguid I, Sjöström PJ (2006) Novel presynaptic mechanisms for coincidence detection in synaptic plasticity. Curr Opin Neurobiol 16:312-322.

Duguid IC, Smart TG (2004) Retrograde activation of presynaptic NMDA receptors enhances GABA release at cerebellar interneuron-Purkinje cell synapses. Nat Neurosci 7:525-533.

Feldman DE (2000) Timing-based LTP and LTD at vertical inputs to layer II/III pyramidal cells in rat barrel cortex. Neuron 27:45-56.

Feller MB, Scanziani M (2005) A precritical period for plasticity in visual cortex. Curr Opin Neurobiol 15:94-100.

Fox K, Zahs K (1994) Critical period control in sensory cortex. Curr Opin Neurobiol 4:112-119.

Fox K, Sato H, Daw N (1989) The location and function of NMDA receptors in cat and kitten visual cortex. J Neurosci 9:2443-2454.

Frenkel MY, Bear MF (2004) How monocular deprivation shifts ocular dominance in visual cortex of young mice. Neuron 44:917-923.

Froemke RC, Dan Y (2002) Spike-timing-dependent synaptic modification induced by natural spike trains. Nature 416:433-438.

Froemke RC, Poo MM, Dan Y (2005) Spike-timing-dependent synaptic plasticity depends on dendritic location. Nature 434:221-225. 
Gordon JA, Stryker MP (1996) Experience-dependent plasticity of binocular responses in the primary visual cortex of the mouse. J Neurosci 16:3274-3286.

He HY, Hodos W, Quinlan EM (2006) Visual deprivation reactivates rapid ocular dominance plasticity in adult visual cortex. J Neurosci 26:2951-2955.

Hensch TK (2004) Critical period regulation. Annu Rev Neurosci 27:549-579.

Hirsch JA (1995) Synaptic integration in layer IV of the ferret striate cortex. J Physiol 483:183-199.

Hofer SB, Mrsic-Flogel TD, Bonhoeffer T, Hubener M (2006) Lifelong learning: ocular dominance plasticity in mouse visual cortex. Curr Opin Neurobiol 16:451-459.

Horton JC, Hocking DR (1996) An adult-like pattern of ocular dominance columns in striate cortex of newborn monkeys prior to visual experience. J Neurosci 16:1791-1807.

Humeau Y, Shaban H, Bissiere S, Luthi A (2003) Presynaptic induction of heterosynaptic associative plasticity in the mammalian brain. Nature 426:841-845.

Iwasato T, Datwani A, Wolf AM, Nishiyama H, Taguchi Y, Tonegawa S, Knopfel T, Erzurumlu RS, Itohara S (2000) Cortex-restricted disruption of NMDAR1 impairs neuronal patterns in the barrel cortex. Nature 406:726-731.

Jo J, Ball SM, Seok H, Oh SB, Massey PV, Molnar E, Bashir ZI, Cho K (2006) Experience-dependent modification of mechanisms of long-term depression. Nat Neurosci 9:170-172.

Jourdain P, Bergersen LH, Bhaukaurally K, Bezzi P, Santello M, Domercq M, Matute C, Tonello F, Gundersen V, Volterra A (2007) Glutamate exocytosis from astrocytes controls synaptic strength. Nat Neurosci 10:331-339.

Katagiri H, Fagiolini M, Hensch TK (2007) Optimization of somatic inhibition at critical period onset in mouse visual cortex. Neuron 53:805-812.

Katz LC, Shatz CJ (1996) Synaptic activity and the construction of cortical circuits. Science 274:1133-1138.

Lauri SE, Vesikansa A, Segerstrale M, Collingridge GL, Isaac JT, Taira T (2006) Functional maturation of CA1 synapses involves activitydependent loss of tonic kainate receptor-mediated inhibition of glutamate release. Neuron 50:415-429.

Le Meur K, Galante M, Angulo MC, Audinat E (2007) Tonic activation of NMDA receptors by ambient glutamate of non-synaptic origin in the rat hippocampus. J Physiol (Lond) 580:373-383.

Li YH, Han TZ (2007) Glycine binding sites of presynaptic NMDA receptors may tonically regulate glutamate release in the rat visual cortex. J Neurophysiol 97:817-823.

Lien CC, Mu Y, Vargas-Caballero M, Poo MM (2006) Visual stimuliinduced LTD of GABAergic synapses mediated by presynaptic NMDA receptors. Nat Neurosci 9:372-380.

Lieske SP, Ramirez JM (2006) Pattern-specific synaptic mechanisms in a multifunctional network. II. Intrinsic modulation by metabotropic glutamate receptors. J Neurophysiol 95:1334-1344.

Lisman J, Raghavachari S (2006) A unified model of the presynaptic and postsynaptic changes during LTP at CA1 synapses. Sci STKE 2006:re11.

Malenka RC, Bear MF (2004) LTP and LTD: an embarrassment of riches. Neuron 44:5-21.

Mameli M, Carta M, Partridge LD, Valenzuela CF (2005) Neurosteroidinduced plasticity of immature synapses via retrograde modulation of presynaptic NMDA receptors. J Neurosci 25:2285-2294.

Mayer MC, Westbrook GL, Guthrie PB (1984) Voltage dependent block by magnesium of NMDA responses in spinal cord neurones. Nature 309:261-267.

Meldrum BS (2000) Glutamate as a neurotransmitter in the brain: review of physiology and pathology. J Nutr 130:1007S-1015S.

Monyer H, Sprengel R, Schoepfer R, Herb A, Higuchi M, Lomeli H, Burnashev N, Sakmann B, Seeburg PH (1992) Heteromeric NMDA receptors: molecular and functional distinction of subtypes. Science 256:1217-1221.

Mower GD, Caplan CJ, Christen WG, Duffy FH (1985) Dark rearing prolongs physiological but not anatomical plasticity of the cat visual cortex. J Comp Neurol 235:448-466.
Nase G, Weishaupt J, Stern P, Singer W, Monyer H (1999) Genetic and epigenetic regulation of NMDA receptor expression in the rat visual cortex. Eur J Neurosci 11:4320-4326.

Nosyreva ED, Huber KM (2005) Developmental switch in synaptic mechanisms of hippocampal metabotropic glutamate receptor-dependent longterm depression. J Neurosci 25:2992-3001.

Nowak L, Bregostovski P, Ascher P, Herbert A, Prochiantz A (1984) Magnesium gates glutamate-activated channels in mouse central neurones. Nature 307:462-465.

Pouzat C, Hestrin S (1997) Developmental regulation of basket/stellate cell $\rightarrow$ Purkinje cell synapses in the cerebellum. J Neurosci 17:9104-9112.

Quinlan EM, Philpot BD, Huganir RL, Bear MF (1999a) Rapid, experiencedependent expression of synaptic NMDA receptors in visual cortex in vivo. Nat Neurosci 2:352-357.

Quinlan EM, Olstein DH, Bear MF (1999b) Bidirectional, experiencedependent regulation of $\mathrm{N}$-methyl-D-aspartate receptor subunit composition in the rat visual cortex during postnatal development. Proc Natl Acad Sci USA 96:12876-12880.

Rakic P (1977) Prenatal development of the visual system in rhesus monkey. Philos Trans R Soc Lond B Biol Sci 278:245-260.

Reyes A, Sakmann B (1999) Developmental switch in the short-term modification of unitary EPSPs evoked in layer 2/3 and layer 5 pyramidal neurons of rat neocortex. J Neurosci 19:3827-3835.

Rumpel S, Kattenstroth G, Gottmann K (2004) Silent synapses in the immature visual cortex: layer-specific developmental regulation. J Neurophysiol 91:1097-1101.

Sah P, Hestrin S, Nicoll RA (1989) Tonic activation of NMDA receptors by ambient glutamate enhances excitability of neurons. Science 246:815-818.

Sasaki YF, Rothe T, Premkumar LS, Das S, Cui J, Talantova MV, Wong HK, Gong X, Chan SF, Zhang D, Nakanishi N, Sucher NJ, Lipton SA (2002) Characterization and comparison of the NR3A subunit of the NMDA receptor in recombinant systems and primary cortical neurons. J Neurophysiol 87:2052-2063.

Sengpiel F, Kind PC (2002) The role of activity in development of the visual system. Curr Biol 12:R818-R826.

Silver RA, Lubke J, Sakmann B, Feldmeyer D (2003) High-probability uniquantal transmission at excitatory synapses in barrel cortex. Science 302:1981-1984.

Sjöström PJ, Turrigiano GG, Nelson SB (2003) Neocortical LTD via coincident activation of presynaptic NMDA and cannabinoid receptors. Neuron 39:641-654.

Smith SL, Trachtenberg JT (2007) Experience-dependent binocular competition in the visual cortex begins at eye opening. Nat Neurosci 10:370-375.

Stryker MP, Harris WA (1986) Binocular impulse blockade prevents the formation of ocular dominance columns in cat visual cortex. J Neurosci 6:2117-2133.

Taha SA, Stryker MP (2005) Molecular substrates of plasticity in the developing visual cortex. Prog Brain Res 147:103-114.

Thoreson WB, Ulphani JS (1995) Pharmacology of selective and nonselective metabotropic glutamate receptor agonists at L-AP4 receptors in retinal ON bipolar cells. Brain Res 676:93-102.

Volgushev M, Kudryashov I, Chistiakova M, Mukovski M, Niesmann J, Eysel UT (2004) Probability of transmitter release at neocortical synapses at different temperatures. J Neurophysiol 92:212-220.

Woodhall G, Evans DI, Cunningham MO, Jones RS (2001) NR2Bcontaining NMDA autoreceptors at synapses on entorhinal cortical neurons. J Neurophysiol 86:1644-1651.

Yang J, Woodhall GL, Jones RS (2006) Tonic facilitation of glutamate release by presynaptic NR2B-containing NMDA receptors is increased in the entorhinal cortex of chronically epileptic rats. J Neurosci 26:406-410.

Yashiro K, Corlew R, Philpot BD (2005) Visual deprivation modifies both presynaptic glutamate release and the composition of perisynaptic/extrasynaptic NMDA receptors in adult visual cortex. J Neurosci 25:11684-11692.

Yasuda H, Barth AL, Stellwagen D, Malenka RC (2003) A developmental switch in the signaling cascades for LTP induction. Nat Neurosci 6:15-16. 